\title{
Diagnóstico biofísico y socioeconómico de la cuenca Bilwi Tingni, Puerto Cabezas, RAAN'
}

\author{
Ulises Cordón Suárez? \\ Wilfredo Johnson ${ }^{8}$ \\ Enrique Cordón Suárez ${ }^{9}$
}

\section{Resumen}

Este estudio presenta los resultados de un diagnóstico biofísico y socioeconómico realizado sobre la cuenca Bilwi Tingni. Esta cuenca es de mucho valor social y ambiental para la ciudad de Bilwi, ya que en ella confluye el $50 \%$ del territorio de la ciudad: todo su sistema tributario y redes de drenaje que atraviesan 23 de los 26 barrios que conforman toda la ciudad, facilitando el escurrimiento de las lluvias.

El estudio es descriptivo y de corte transversal, tomando como referencia el período 2008. El universo del estudio lo comprende toda el área de la cuenca Bilwi Tingni con una extensión de 16.01 km². Para la descripción de los componentes biofísicos se definieron tres secciones de trabajo: la zona alta, media y baja, en donde se registró detalladamente las variables biofísicas y ambientales; en cambio, la información socioeconómica fue a través de entrevistas abiertas con los pobladores de los barrios, las autoridades municipales y comunales.

La cuenca Bilwi Tingni es pequeña y de forma ovalada, su uso predominante es urbano para el establecimiento de la infraestructura de la ciudad, aunque muy desordenada. De igual manera es una cuenca exorreica ya que su drenaje principal se dirige hacia el mar Caribe, sector de la bocanita. Su cobertura vegetal es mínima cubriendo únicamente el $8 \%$ del área total. La fauna predominante se compone de aves, crustáceos y en menor cantidad reptiles. El análisis bacteriológico del agua refleja un nivel de contaminación muy significativo, especialmente en la zona baja, por lo cual no es apta para el consumo humano ni animal; sin embargo, la parte alta puede ser utilizada para lavado de ropa y baño.

En la zona media de la cuenca se concentran el 72\% de los barrios de la ciudad de Bilwi y es donde se aglutina la mayor intervención antropogénica. Los principales problemas de la

6 Estudio realizado con el financiamiento del proyecto PATHWAY II "Support to Graduation Research Projects of Indigenous and Afro Descendant Students in URACCAN”, de la Fundación FORD.

7 Ingeniería Agroforestal del recinto URACCAN BILWI.

8 Ingeniería Agroforestal del recinto URACCAN BILWI.

9 Coordinador de la carrera de Ingeniería Agroforestal del recinto URACCAN BILWI. Tutor de la monografía. 
cuenca son: La falta de interés de la población por su protección, el desorden urbanístico, altas concentraciones de desechos sólidos en diferentes sitios y poca cobertura vegetal.

Palabras claves: Morfometría, zonas de vida, cuenca Bilwi Tingni.

\section{Introducción}

El diagnóstico de una cuenca es un requisito indispensable para planificar el ordenamiento y sostenibilidad de los recursos naturales, a saber que permite identificar las potencialidades y limitaciones de sus recursos en beneficio de los pobladores que habitan el área. En el caso de la ciudad de Bilwi, cabecera del municipio de Puerto Cabezas, esta es atravesada por la cuenca pequeña Bilwi Tigni, y sobre ella se han construido los cimientos de la ciudad sin ningún plan de ordenamiento.

En conversación con algunos habitantes de la cuenca, se refleja que antes de los años 80 , esta cuenca se encontraban en un mejor estado biofísico, con más del $80 \%$ de su área cubierta de vegetación muy diversa, sus afluentes eran pequeños pero muy vivos, el agua circulaba constantemente durante todo el año y algunos sitios (pozas) servían como espacios de pesca y caza (cusucos y garrobos) para muchos pobladores, a simple vista no se veía afectación de sus recursos naturales: flora y fauna; no obstante, con la guerra civil de los años ochenta, gran parte de la población comunitaria y de otros municipios, emigró hacia la ciudad de Bilwi, asentándose de manera desordenada en las periferias de la ciudad. Posteriormente con el incremento poblacional se edificaron construcciones de madera y concreto desordenadamente, se delimitaron los terrenos, y se inició la extracción de materiales de construcción (arena y grava) de manera intensiva, siendo la parte alta y media de la cuenca las más afectadas.

Actualmente esta cuenca presenta problemas críticos de deterioro visualizados a través de la pérdida del caudal de agua de los ríos, un desorden urbanístico, cercas de propiedades que bloquean el drenaje natural y provocan inundaciones constantes, y un significativo grado de contaminación provocada principalmente por la acumulación de desechos sólidos (basura) y líquidos. En épocas de verano la parte alta de la cuenca se seca totalmente reflejando la gran acumulación de desechos sólidos diversos; por otro lado, en época de invierno y con el aumento del caudal de agua, toda esta basura acumulada bloquea el paso libre del agua provocando en su recorrido inundaciones en algunos sectores, perjudicando a sus pobladores y favoreciendo la diseminación de enfermedades. 
Con este diagnóstico pretendemos crear una herramienta básica para definir acciones de saneamiento y conservación.

\section{Revisión de literatura}

Morales Jairo (1999:1), define una cuenca como: "un territorio que es delimitado por la propia naturaleza esencialmente por los limites de la zonas de escurrimiento de las aguas superficiales que convergen hacia un mismo cauce... la cuenca, sus recursos naturales y sus habitantes poseen condiciones físicas, biológicas económicas, sociales y culturales que les confieren características que son particulares de cada una". Este concepto de Morales demuestra claramente que la cuenca es una unidad integral que no puede estar desligada de la naturaleza misma y la población que la habita, ya que el agua y el suelo es la fuente de vida para el ser humano.

Morales Jairo (2000) plantea que el diagnóstico de una cuenca constituye un requisito indispensable para planificar e implementar proyectos de desarrollo orientados con el fin de lograr el uso sostenible de los recursos naturales, considerando las potencialidades y limitantes de estos recursos. Esto incluye conocer los elementos naturales y sociales que se interrelacionan entre sí para dar vida a la misma. Los propósitos básicos de un diagnóstico son: conocer las potencialidades, los problemas del área, sus causas, y los efectos relacionados con las actividades que se desarrollan. Esto con el miramiento de interpretar las situaciones que se presentan con el fin de formular acciones viables para ofrecer buenos servicios.

De igual manera Miranda y Pereira (2000:3), mencionan que los componentes que se encuentran interactuando o en combinación en una cuenca hidrográfica, son:

\begin{tabular}{ll}
\hline \multicolumn{1}{c}{ Aspectos biofísicos } \\
\hline Localización & Límites, latitud y longitud, comunidades. \\
\hline Fisiografía y relieve & Cordilleras, elevaciones, paisajes. \\
\hline Morfometría & $\begin{array}{l}\text { Superficies (ha), elevaciones (msnm), pendiente (\%), longitud de los } \\
\text { cursos de agua, perfiles de los causes principales, pendiente de los } \\
\text { ríos principales, red de drenaje. }\end{array}$ \\
\hline Geología & Origen, procesos formación o cambios en el suelo. \\
\hline Suelos & $\begin{array}{l}\text { Clasificación de los Suelos de la Cuenca, Usos actuales, } \\
\text { capacidad de uso, áreas críticas por medio del uso de la tierra. }\end{array}$ \\
\hline
\end{tabular}




\begin{tabular}{|c|c|}
\hline Zonas de vida & Mapa ecológico, tipos y zonas. \\
\hline Clima & $\begin{array}{l}\text { Precipitación, temperatura, velocidad de viento y evapotranspira- } \\
\text { ción. }\end{array}$ \\
\hline Hidrológica & $\begin{array}{l}\text { Potencial hídrico, potencialidades de crecientes, calidad de agua, } \\
\text { determinación del caudal. }\end{array}$ \\
\hline $\begin{array}{l}\text { Vegetación } \\
\text { (Bosques) }\end{array}$ & $\begin{array}{l}\text { Especies predominantes, zonas de explotación, deterioro, tipo de } \\
\text { recursos, zonas potenciales (Tipos de bosques, especies, densidad, } \\
\text { altura, diámetro, volumen, Fauna silvestre). }\end{array}$ \\
\hline Vida silvestre & Habitad de la cuenca, especies. \\
\hline Parques & Describir si existen áreas protegidas. \\
\hline \multicolumn{2}{|r|}{ Aspectos socioeconómicos } \\
\hline Población & $\begin{array}{l}\text { Densidad poblacional, distribución, tenencia de la tierra, presión } \\
\text { sobre los recursos. }\end{array}$ \\
\hline $\begin{array}{l}\text { Situación de la } \\
\text { población }\end{array}$ & Organizaciones, servicios públicos básicos, infraestructura, vivienda. \\
\hline Economía & $\begin{array}{l}\text { Actividades de trabajo, (madera, minas pesca, turismo, y como influ- } \\
\text { ye sobre los recursos de la cuenca), propiedad de la tierra. }\end{array}$ \\
\hline $\begin{array}{l}\text { Situación institu- } \\
\text { cional y legal }\end{array}$ & $\begin{array}{l}\text { Apoyo de las autoridades, ONG's presentes, planes, programas, leyes } \\
\text { de protección. }\end{array}$ \\
\hline
\end{tabular}

Todos estos componentes se encuentran en una interacción dinámica y armónica: son interdependientes, por tanto serán motivo básico de nuestra investigación el conocerlos en la cuenca de Bilwi Tigni.

\subsection{El diagnóstico biofísico}

Permite conocer los elementos bióticos, abióticos y fisiográficos que se interrelacionan en un medio natural. El diagnóstico de una cuenca generalmente se orienta para conocer en detalle estos elementos, por tanto es necesario establecer un patrón de orden dentro de la cuenca a través de una definición de sus partes.

De acuerdo a Rodríguez (1996), citado en Morales 2000, las partes constitutivas de una cuenca hidrográfica son las siguientes: 


\section{RECURSOS NATURALES Y MEDIO AMBIENTE}

\section{Cuenca de recepción}

Es la región alta de una cuenca donde se reúne la casi totalidad de las precipitaciones y de ella proviene el caudal líquido originado por las tormentas como también el caudal sólido; es en esta zona donde presentan los fenómenos erosivos.

\section{Garganta}

Es el canal por donde transita el caudal sólido y líquido del torrente. El total del material transportado (Caudal sólido) se origina tanto del material erosivo proveniente de la cuenca de recepción como la de la erosión de los diversos cauces de esta.

\section{Zona de depósito}

Es el lugar de depósito o sedimentación según sea si el régimen hidrológico es de carácter torrencial o fluvial; el material transportado por la garganta y las diversas formas que presenta obedece a la dinámica geomorfológico.

\section{Canal de desagüe}

Esta parte constitutiva de una Cuenca es inherente a los ríos torrenciales y constituye una zona en que las aguas han quedado libres de acarreos. Consideramos que esta clasificación es un tanto general para poder desarrollar un diagnóstico; empero, nos permitirá organizar nuestro trabajo de levantamiento de datos en el campo, a través de la definición de las zonas de mayor impacto natural.

\section{El diagnóstico socioeconómico}

Antes de comenzar a hacer un estudio detallado de una cuenca hidrográfica o su derivación, debemos de recolectar y analizar la información socioeconómica de la zona, ya que estos informes proporcionan a los gestores y planificadores mucha información básica que puede ser valiosa para la preparación de propuestas de estudios y/ de trabajo. Según Morales (2000): "el contenido de un estudio socioeconómico abarca un vasto conjunto de condiciones sociales y actividades económicas en una cuenca hidrográfica nos permite conocer la realidad de la cuenca y proponer alternativas de solución, debido a que el factor social hombre-comunidad son la clave para movilizar las acciones de manejo de cuencas, por ello es necesario realizar la interpretación cuidadosa de sus respectivas características socioeconómicas". Mediante este diagnóstico se conoce la demanda de la población, sus problemas, sus necesidades, sus tendencias, y conflictos con la capacidad de carga de la cuenca. Aquí se incluyen los elementos sociales, culturales, legales, administrativos e institucionales. Morales 
(:19), precisa que "es importante entender porque el hombre hace lo que hace, como valorar sus conocimientos tradicionales y entender sus actitudes”.

\section{Diseño metodológico}

La idea inicial de esta investigación surgió del desarrollo de una práctica de campo en la asignatura de cuencas hidrográficas que realizamos cuando fuimos estudiantes de la carrera de Ingeniería agroforestal (2002-2006).

El estudio es descriptivo y de corte transversal, tomando como referencia el período 2008. Su área de estudio comprende la ciudad de Bilwi con sus 23 barrios afectados. Inicia en la parte norte de la ciudad y finaliza en el Sur, sector de la bocanita. El universo comprende toda el área de la cuenca Bilwi Tingni que tiene una extensión de $16.01 \mathrm{~km}^{2}$, cubriendo el 50\% del territorio de la ciudad de Bilwi.

Para la descripción de los componentes biofísicos se definieron tres secciones de trabajo: la zona alta, media y baja de la cuenca, según metodología descrita por Morales (2000). Se realizó una estratificación y un registro detallado de las variables biofísicas y ambientales.

Para el levantamiento de los datos de suelo se realizaron tres calicatas. Una en cada sección de trabajo, con profundidad de un metro cada una. Aquí se evaluaron las variables edafológicas, tales como: caracterización de horizontes, profundidad de la capa fértil, color y textura. De igual manera se establecieron dos parcelas de muestreo para cada sección de trabajo, seis en total. Cada parcela con un área de $20 \mathrm{~m}$ de diámetro para pinares y 10x10 m en manglares. Se les tomaron datos de: especies, densidad, altura, DAP, y vida silvestre (fauna). También se realizaron dos análisis: físico y bacteriológico del agua, evaluando cantidad de coliformes totales y e. Coli.

La recopilación de la información socioeconómica, se realizó a través de entrevistas abiertas a los pobladores de los barrios antes mencionados. Para esto se entrevistaron a las autoridades municipales y habitantes de los barrios: Los Ángeles, Alemán, Nueva Jerusalén, Spanish Town y El Muelle (Veinte personas en total).

\section{Resultados y discusión}

La cuenca Bilwi Tingni se encuentra ubicada en la Región Autónoma del Atlántico Norte (RAAN) de la Costa Caribe nicaragüense, cubre parte de los territorios de las 
comunidades de Tuapi, Kamla y la Ciudad de Bilwi. Se extiende de Norte a Sur con un área total de $16.0125 \mathrm{~km}^{2}$, desemboca sus aguas directamente en el mar Caribe, en el sector de la bocanita del barrio El muelle de la ciudad de Bilwi. Sus coordenadas geográficas son: longitud Norte $14^{\circ} 02^{\prime} 32.2^{\prime \prime}$ y $83^{\circ} 23^{\prime} 39.1^{\prime \prime}$ latitud Oeste.

\subsection{Aspectos biofísicos}

La zona alta se ubica en el sector del Sw de la comunidad de Tuapi, aquí se origina la naciente del río Bilwi Tigni y parte del sector donde se ubica la empresa de mariscos CARODI ${ }^{10}$, cubre totalmente el barrio "El Galileo" en la salida de Bilwi o el retén. Esta zona se caracteriza por muy poca cobertura vegetal, abundantes cráteres en el suelo por la extracción de materiales de construcción, sus elevaciones no sobrepasan los $40 \mathrm{msnm}$. Actualmente es el sitio hacia donde se orienta el crecimiento de la ciudad de Bilwi, por tanto es de gran utilidad desarrollar un programa de ordenamiento. La zona media cubre entre los barrios "El Galileo" y "Los Ángeles", es un área muy poblada, con abundantes construcciones de madera y concreto; sin embargo, muy desordenada. El río NIPCO ${ }^{11}$ afluente de la cuenca Bilwi Tigni atraviesa totalmente el barrio "Los Ángeles", pasando por mercados, hospitales, escuelas, etc. Es una de las zonas más desordenada y afectada por las inundaciones durante los inviernos copiosos y generalmente se requiere de evacuaciones constantes. La zona baja, abarca desde el barrio "Los Ángeles" hasta su desembocadura en el mar Caribe, sector de la bocanita en el barrio el muelle (Mapa de ubicación y zona). Es una zona con una leve productividad, se siembra un poco musáceas, yuca, caña, cítricos y cocos. Es la zona más plana pero con la mayor degradación ambiental y es el sitio de mayor acumulación de los desechos, el cual se refleja en la calidad del agua.

El área de drenaje de la cuenca es de $16.01 \mathrm{~km}^{2}$ abarca desde su naciente en el empalme de Tuapi (a $3 \mathrm{~km}$. de la ciudad de Bilwi) hasta su desembocadura en el mar Caribe, clasificándose así como una cuenca exorreica. La zona alta se caracteriza por tener las mayores pendientes, cubre una extensión de $4.46 \mathrm{~km}^{2}$. En cambio la zona media tiene una extensión de $8.28 \mathrm{~km}^{2}$ con pendientes moderadas, cuenta con dos tributarios y es la zona más poblada por cubrir la mayor parte de la ciudad de Bilwi. Así también la zona baja de la cuenca posee una extensión de $3.37 \mathrm{~km}^{2}$, es el área donde se encuentra la mayor densidad del bosque, constituyendo éste principalmente del tipo manglar y la mayor diversidad de fauna. Es el sector que desemboca hacia el mar Caribe.

La cuenca se encuentra en el rango promedio del $0.7 \%$ de pendiente, la mayor parte de su área es plana y se encuentra en un tipo de terreno entre suave y llano del litoral

10 CARODI: Empresa de mariscos privada

11 NIPCO: Nicaraguan Pine Company 
de la Costa Caribe. Su forma es ovalada con dimensiones de $7.15 \mathrm{Km}$. de largo y 3.65 $\mathrm{Km}$ de ancho, este dato está relacionado a la velocidad con que escurre el agua y llega al cauce principal. Teóricamente se sabe que cuando una cuenca tiene forma redonda u ovalada presentan mayores posibilidades de generar avenidas torrenciales que cuencas alargadas. Es una de las razones por la que la cuenca Bilwi Tingni se inunde tan seguido con apenas unas horas de lluvias. Esto amerita planificar y desarrollar actividades de protección y conservación de la cuenca.

De igual manera el área de la cuenca cuenta con un cauce principal y dos afluentes que recepcionan el agua proveniente de las precipitaciones y alimentan la corriente principal. De acuerdo a la teoría de Horton la cuenca Bilwi Tingni se categoriza como una cuenca pobremente drenada por lo tanto es de lenta respuesta hidrológica ante las precipitaciones. Horton $(1,945)$ definió la frecuencia de corrientes o cauces, como la relación entre el número de cauces y su área correspondiente, y sobre la base del cálculo se encontró que la cuenca Bilwi Tigni posee un deficiente sistema de drenaje debido a una baja frecuencia de corrientes, este es un indicador de deficiencia hidrológica, en una relación: a mayor número de corrientes, mayor frecuencia y mayor eficiencia de drenaje.

La cuenca Bilwi Tingni se encuentra dentro de las llanuras costeras del Caribe, es de origen aluvión, compuesto de materiales recientes no consolidados tales como la arena, arcilla, cantos, rodados y gravas que provienen de la descomposición y de la erosión de las sierras septentrionales y de las serranías volcánicas antiguas (AID/RIC 1996:14). Los suelos de la zona alta tienen una textura predominantemente franco arcilloso en el horizonte $A$, con una profundidad de $12 \mathrm{~cm}$, con un color que va de negro en la parte más superficial (humus) hasta café gris en el resto de la capa. En el horizonte B se halla una mezcla de arcilla de color rojizo y abundantes rocas. Los suelos de la zona media tienen una textura predominantemente arcillosa en su horizonte $\mathrm{A}$, posee una profundidad de $15 \mathrm{~cm}$, y su color va de café oscuro en la parte más superficial (humus) hasta gris en el resto de la capa. En el horizonte B tiene una profundidad de más de $85 \mathrm{~cm}$, y es de color rosado, causado probablemente por una acumulación de hierro (ver foto adjunta). Los suelos de la zona baja tienen una textura predominantemente franco arcilloso en el horizonte A $(15 \mathrm{~cm})$, con un color que va de gris a oscuro en parte más superficial (humus) hasta café gris en el resto de la capa. En el horizonte $B$ se observa una coloración rojiza y rosada, con una mezcla de arcillas y piedras.

Las zonas de vida de la cuenca se caracterizan por tres formaciones vegetales azonales con un conjunto de ámbitos específicos, producto de los factores climáticos imperantes en la zona. Estos son: Bosque perennifolio de zona moderadamente cálida, esto corresponde a los bosque de pinares, que se encuentran principalmente en la zona alta y 
media de la cuenca. Bosque perennifolio de zonas modernamente cálidas y húmedas, corresponde a bosques de pinares y latifoliada que se encuentra a orilla de los ríos y caños. Bosque de zona muy húmeda y fresca en su desembocadura, corresponde a los manglares de la zona baja de la cuenca.

Las características climáticas son de 3,242 mm de precipitación media anual y de altura que va de 0 a $40 \mathrm{msnm}$. El régimen lluvioso predomina de mayo a diciembre y es julio el mes más lluvioso, alcanzando un promedio de $500 \mathrm{~mm}$.

El uso del suelo de la zona alta está conformada por una vegetación rala de Pinus caribaea de edad joven y vegetación característica de bosques de galería, dentro de esta zona se hayan dos aserraderos privados de madera y una planta procesadora de mariscos (CARODI), así también una bloquera. La zona media conforma la mayor parte de la cuenca y cubre casi toda la ciudad, los tipos de bosques encontrados en esta parte son bosques de galería en su mayoría y pinares, en esta zona se encuentra el aeropuerto internacional, la empresa procesadora de madera (MADENSA ${ }^{12}$ ) y un aserrillo de madera. Algunas familias poseen huertos en sus predios con cultivos de frutales, musáceas y tubérculos. De las tres zonas ésta es la más poblada por lo tanto es donde se da el mayor impacto de deterioro y la mayor acumulación de desechos sólidos de la cuenca. La zona baja está conformada por bosque de galería, manglares y huertos familiares, en comparación a las dos primeras zonas de la cuenca en esta se encontraron más cantidad de huertos familiares. Aquí se encuentra la estación de fibra óptica (ARCO 1).

Las áreas más afectadas por intervención humana son a través de la extracción de madera, materiales de construcción y establecimiento desordenado de casas en las orillas del río mismo y el bosque de galería constituyendo los puntos con mayores indicadores de degradación la zona media y baja, que es utilizada como vertedero de basura.

Con relación a su composición hidrológica esta posee dos afluentes con corrientes efímeras que abastecen el cauce principal únicamente en época de invierno. No obstante, el cauce principal en su parte alta contiene agua durante todo el año con características más sanas y es utilizado por los habitantes del barrio San Judas para el lavado de ropa y el baño. Según análisis de agua realizada por el laboratorio de ENACAL ${ }^{13}$, el agua del río Bilwi Tigni es de mala calidad ya que presenta un alto grado de contaminación con heces fecales y químicos provenientes del hospital regional, por tanto no es apta para consumo humano; sin embargo, a partir de la parte alta de la cuenca el análisis

12 Maderas derivados de Nicaragua S.A.

13 Empresa Nicaragüense de Acueductos y Alcantarillados 
químico refleja una disminución considerable de los niveles de contaminación y que permite desarrollar ciertas actividades tales como: lavado de ropa y baño. Actualmente el uso que se le está dando es correspondiente con su calidad, ya que la población local la utiliza para lavado de ropa y baño.

Con respecto a la vegetación, la zona alta posee una vegetación bastante rala que cubre cerca del $4 \%$ del territorio. Predominan los pinares jóvenes (Pinus caribea) con diámetros promedios de $15.6 \mathrm{~cm}$ y altura promedio de $6.8 \mathrm{~m}$, su densidad no sobrepasa los 70 árboles por hectárea. Estos pinares se encuentran distribuidos de manera agrupada y asociada a lo largo de la zona, con otras especies latifoliadas como: Cecropia obtusifolia (Guarumo), Byrsonima crasifolia (Nancite), Cuaratella americana (Chaparro), Acoelorraphe wrightii (palma papta), Chrysobalanus icaco (icacos) y una gran variedad de especies de la familia de las Melastomastacias y gramíneas. La zona media está conformada en su mayoría por bosques latifoliados de galería, predominando nuevamente nancite, chaparro, icacos y algunas gramíneas. La zona baja se caracteriza por la presencia dominante de bosque de manglares, que se ubica en su mayoría en la desembocadura del río, predominando las especies Rhizophora mangle (Mangle rojo), Laguncularia racemosa (mangle blanco) y Avicennia germinans (mangle negro). Estas son tres de las cuatro especies de mangle de toda la región, siendo un indicador de gran importancia biológica, considerando los usos y valor biológico de esta especie.

La fauna característica de toda la cuenca Bilwi Tigni se concentra principalmente en la zona baja. Las especies más representativas de aves son: garza blanca (Ardea alba), pato salvaje (Anas plathyrynchos), zanate (Quiscalus mexicanus), martín pescador. También algunos crustáceos como el cangrejo azul (Cardisoma guanhumi), cangrejo violinista y algunos reptiles como la iguana verde (Iguana iguana).

En relación al clima de la cuenca Bilwi Tingni, las precipitaciones promedios son de $3,242 \mathrm{~mm}$; y los meses más lluviosos son junio y julio que alcanzan un promedio máximo mensual de $483.57 \mathrm{~mm}$, en cambio los meses más secos son febrero, marzo y abril con promedios mensual de $80.16 \mathrm{~mm}$, según estos datos de registro de precipitaciones y la observación directa consideramos que cada año hay al menos tres inundaciones del río. 
PRECIPITACIÓN MEDIA ANUAL (2000-2007)

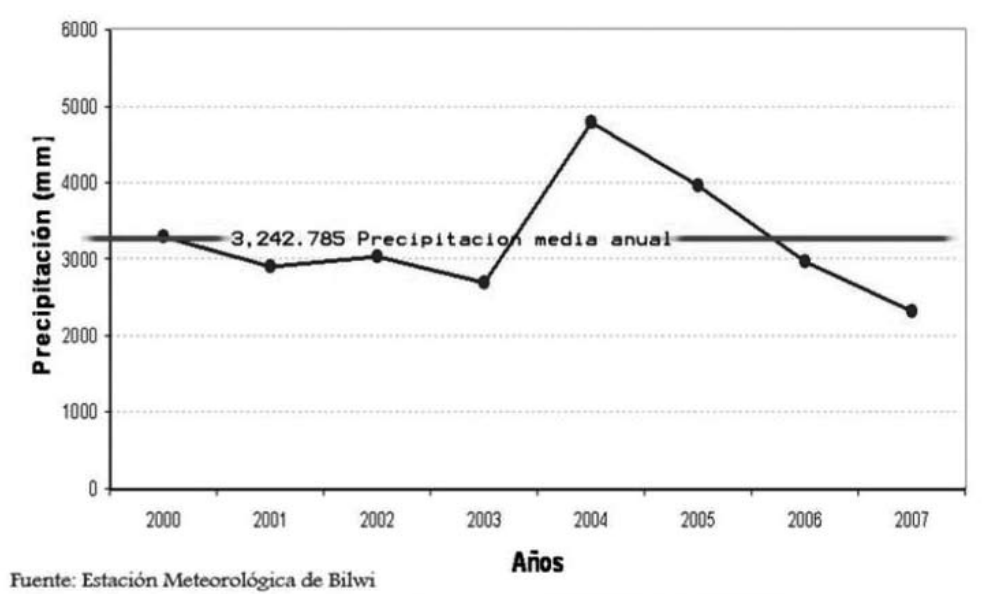

Figura No. 1. Precipitaciones media anuales (2000-2007)
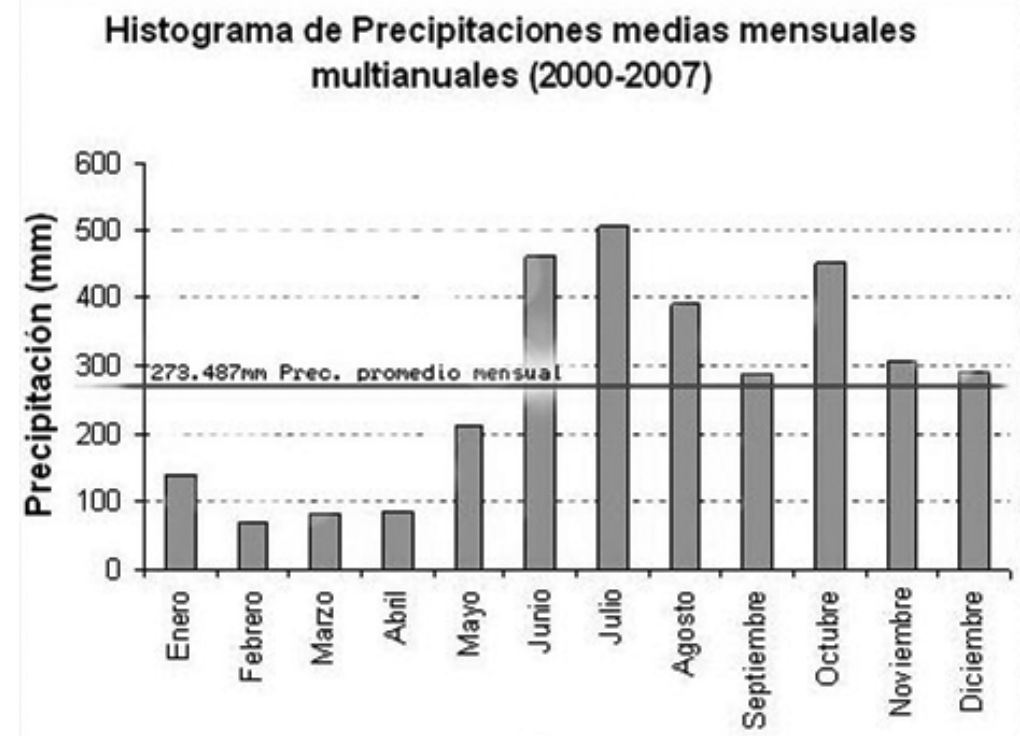

Meses

Figura No. 2. Precipitaciones medias mensuales multianuales (2000-2007)

La velocidad del viento en el área de estudio es de una media anual de $4.4 \mathrm{~m} / \mathrm{s}$ logrando alcanzar su promedio máximo $5 \mathrm{~m} / \mathrm{s}$ durante los meses de julio, noviembre, diciembre y enero. Por otro lado la humedad relativa en el área de estudio es muy constante, 
alcanzando un porcentaje medio anual de $85 \%$. Según los registros de ocho años su comportamiento ha variado únicamente 1 a $3 \%$ por año.

\subsection{Aspectos socioeconómicos}

La economía de Bilwi se caracteriza en su mayoría por actividades de pesca artesanal, empresas privadas y estatales, empleos en las instituciones, ONG's y el comercio.

La pesca artesanal es realizada en el mar Caribe (mar de Bilwi y los cayos Miskitos) mayormente por pescadores originarios de los litorales Norte y Sur que tienen sus domicilios en la ciudad de Bilwi y algunos que viven temporalmente. En el mar de Bilwi se capturan almejas (Vivaldo), peces y camarones con redes o chinchorros que son destinados para el mercado local mientras que las especies capturadas en los cayos son la langosta del caribe o la langosta espinosa (Panulirus argus) y la tortuga verde (Chelonia mydas) a pesar de que esta última está en peligro de extinción. Las instituciones competentes como MARENA ${ }^{14}$, SERENA ${ }^{15}$, INPESCA ${ }^{16}$ y la Alcaldía Municipal de Puerto Cabezas con el propósito de regular el comercio de la tortuga verde han creado limitaciones divulgadas a través de comunicados radiales y escritos, tales como la prohibición del traslado a otros municipios y establecimiento de cuota de capturas por tiempo de veda.

En el caso de la langosta, los pescadores venden sus productos a los centros de acopio ubicados en los cayos y a las empresas procesadoras de mariscos ubicados en la ciudad de Bilwi que luego exportan el producto hacia otros países.

Otra de las actividades con ingreso significativo es el comercio de la madera procesada dentro de la ciudad y fuera del municipio aunque pocas personas practican este negocio.

En el caso de la cuenca de Bilwi Tigni, no se registra ninguna actividad productiva de gran impacto, a excepción de las actividades de servicio y comercio (bares, restaurantes). La mayor parte de la población desarrolla trabajos fuera de la cuenca enfocada en la pesca y forestal.

La ciudad de Bilwi tiene una extensión de $27.21 \mathrm{Km}^{2}$ y la cuenca se encuentra ubicada dentro de esta zona abarcando el $\mathbf{5 0 \%}$ del área total de la ciudad. Esto hace que la

\footnotetext{
14 Ministerio del Ambiente y Recursos Naturales.

15 Secretaría de Recursos Naturales.

16 Instituto Nicaragüense de la Pesca y Acuicultura.
} 
presión ejercida sobre ella, principalmente en el área de la construcción sea bastante significativa y degradante.

La población mayoritaria es de etnia miskitu, y la ciudad cuenta con 26 barrios y según el registro del Policlínico Ernesto Hooker con una población de 48,981 habitantes, la mayoría son inmigradas desde las comunidades cercanas y de otros municipios principalmente Waspam y Prinzapolka. Inmigrados comúnmente con el propósito de trabajar y en busca de educación (secundaria y universitaria). La tenencia de tierra en Bilwi es administrada por la comunidad indígena de Karatá a la que se le paga un canon anual mínimo de $C \$ 500.00$, en cambio las empresas y negocios en general pagan un canon anual de $\$ 40.00$ por pie $^{2}$ de terreno. Los miembros originarios de la comunidad de Karatá se les exoneran tal cuota.

Los gobiernos están conformados por los jueces de los barrios, el gobierno Municipal (la Alcaldía), GRAAN ${ }^{17}$ y el CRAAN ${ }^{18}$. Bilwí es la ciudad cabecera del Municipio de Puerto Cabezas y es a la vez la ciudad más importante de la Región Autónoma del Atlántico Norte (RAAN), en ella se encuentran establecidas las instalaciones del Consejo Regional Autónomo del Atlántico Norte (CRAAN) y el Gobierno Regional Autónomo del Atlántico Norte (GRAAN) con su coordinador de gobierno.

La ciudad de Bilwi cuenta con energía eléctrica, en todo tiempo es de regular calidad y es producida por la empresa $\mathrm{PCP}^{19}$ y distribuido por $\mathrm{ENEL}^{20}$; la mayoría de los barrios tienen acceso al servicio de cable (televisión), cuenta con dos empresas que brindan servicios de telefonía celular, algunos de los barrios tienen acceso al agua potable (20\%) y el resto se abastecen de pozos artesanales. Dentro de la cuenca Bilwi Tingni encontramos un total de dieciocho colegios, veintidós iglesias de diferentes denominaciones, también encontramos servicios de salud como el hospital Nuevo Amanecer, el policlínico y otros centros de salud privados que brindan el servicio de salud a la ciudad de Bilwi. Las actividades sociales identificados en la zona alta de la cuenca Bilwi Tingni son las siguientes: Una escuela primaria que Brinda clases de turnos matutino y vespertino y una Iglesia de religión Morava de la etnia miskitu.

En la zona media se cuenta con las siguientes actividades: catorce escuelas; cuatro primarias, dos colegios exclusivamente secundarios y cinco colegios que brindan las enseñanzas primarias y secundarias. Se hayan once iglesias de diferentes religiones; tres iglesias Moravas, cinco Evangélicas, una Anglicana, una Adventista y una Católica.

17 Gobierno Regional Autónomo del Atlántico Norte.

18 Consejo Regional Autónomo del Atlántico Norte.

19 Puerto Cabezas Power.

20 Empresa Nicaragüense de Electricidad. 
También se encuentra en esta zona el hospital Nuevo Amanecer, la policlínica y otros centros de salud privados como la clínica Bilwi, CADAMUC y la Salud y Familia. En la zona baja se encuentran tres escuelas primarias, una escuela secundaria; siete iglesias Evangélicas, dos Moravas y una Católica.

\subsection{Principales problemas de la cuenca}

La vegetación tiene una fuerte influencia en el régimen hidrológico de la cuenca de Bilwi Tingni, pues este recurso está relacionado con la erosión, temperatura y evaporación de la zona. La degradación de este valioso recurso incide fuertemente en el desequilibrio del resto de los componentes tanto bióticos como abióticos, dando lugar a fenómenos como emigración de la fauna silvestre, inundaciones y por ende surgimiento de epidemias entre otras. De igual manera a profundidades mayores de un metro aún se encuentran desechos sólidos inorgánicos persistentes como botellas de vidrio, latas de aluminio, latas de pintura, embases plásticos, llantas y suelas de zapatos, producto de acumulaciones periódicos.

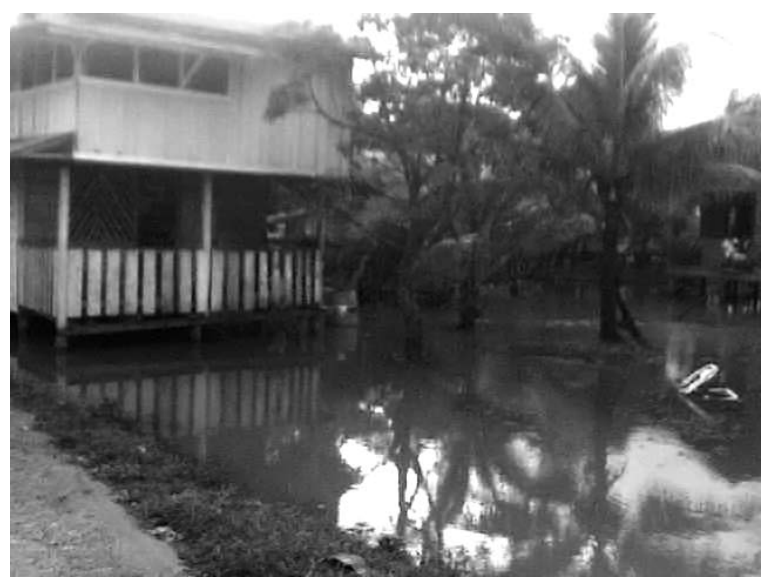

Figura No. 3. Imágenes de construcciones de casas.

Sobre la ribera del río, se encuentra ubicado el mercado de madera y el hospital "Nuevo Amanecer", que son dos de los principales focos de generación y contaminación de la cuenca. En el primero, pobladores del Barrio "los Ángeles" utilizan el cauce del río como vertedero de basura y aguas negras; y en el segundo caso, el hospital es generador de abundantes desechos químicos médicos que son derramados sobre los cauces y que escurren en el río. Otro gran problema es el desorden urbanístico en toda el área de la cuenca, la mayoría de los habitantes construyen sus casas y cercas sin ningún estudio previo de las condiciones del sitio, únicamente obtienen un permiso de la comunidad 
propietaria del sector, la cual puede ser: Karata, Diez comunidades, kamla o Tuapi las cuales cobran un canon de arriendo. En el caso de la municipalidad también se paga un impuesto al catastro que autoriza la construcción. No se visualiza ningún interés de parte de las instituciones en organizar urbanísticamente el territorio de la cuenca. Esto provoca que muchas edificaciones se encuentren construidas sobre los cauces de los tributarios, bloqueando el paso natural del agua y con un mayor incremento poblacional se da la acumulación de basura en diferentes sitios, que bloquean el paso del agua y crean las condiciones para la proliferación de enfermedades.

\section{Conclusiones}

La cuenca Bilwi Tingni es una cuenca pequeña y de forma ovalada, cubre el $50 \%$ del área total de la ciudad de Bilwi y su uso está basado principalmente en el establecimiento de la infraestructura de la ciudad. Es una cuenca exorreica debido a que todo su drenaje se dirige directamente hacia el mar Caribe, sector de la Bocanita. De igual manera posee un deficiente sistema de drenaje debido a su baja densidad y frecuencia de drenaje, esto favorece que se den inundaciones rápidas y constantes en la ciudad de Bilwi.

La cobertura vegetal es mínima cubriendo únicamente el $8 \%$ del área total de la cuenca, en la parte alta predominan bosques de pinares, en la media predominan asociaciones de bosques latifoliados y pinares y en la zona baja manglares. La fauna predominante de la cuenca son aves y crustáceos, y en menor cantidad reptiles. La mayoría se concentra en la zona baja de la cuenca.

El análisis bacteriológico del agua de la cuenca de Bilwi Tigni, refleja un nivel de contaminación muy significativo, especialmente en la zona baja, las aguas de la zona alta y media resultaron no ser potable pero permisible su uso para lavado de ropa, natación, pesca y riego.

En la zona media de la cuenca se ubican el $72 \%$ de los barrios de la ciudad de Bilwi y es donde se concentra la mayor intervención antropogénica. Su economía se caracteriza por desarrollar actividades de pesca, empleos en las instituciones, ONG's y el comercio. Los principales problemas de la cuenca son: La falta de cobertura vegetal es la mayor de la zona que facilita la erosión y sedimentación afluente, también la contaminación de sus aguas y el desorden urbanístico. 


\section{Vl. Bibliografía}

Mendoza Morales, Jairo (1999). Conceptos Básicos de Cuencas Hidrográficas. Managua, Nicaragua. UNA, Managua.

Mendoza Morales, Jairo (1999). Texto Básico de la Asignatura Conservación de Suelos y Agua. Una, Managua.

Miranda Melvin, Pereira Nicolás (2002). Caracterización Biofísica y Socioeconómica de la Subcuenca de Brakira, Comunidad De Tuapi, RAAN. Puerto Cabezas; Bilwi; mayo; 2002. URACCAN, Bilwi.

Http://club.telepolis.com/geografo/general/contaminacion.htm (12 de julio del 2007).

Http://www.csj.gob.sv/leyes.nsf/3bbd868cb40ce9d106256a8400764b33/e6ccad42ac0f6c8e0625715b005674e3 (12 de julio 2007). 